Article

\title{
Restricticin B from the Marine Fungus Penicillium janthinellum and Its Inhibitory Activity on the NO Production in BV-2 Microglia Cells
}

\author{
Byeoung-Kyu Choi ${ }^{1,2}$, Shin-Young Park ${ }^{3}$, Song-Hee Jo ${ }^{3}$, Dong-Kug Choi ${ }^{3}$, Phan Thi Hoai Trinh ${ }^{4,5}$, \\ Hwa-Sun Lee', Cao Van Anh ${ }^{1,2}$, Ngo Thi Duy Ngoc ${ }^{4}$, Tran Thi Thanh Van ${ }^{4,5}$, and Hee Jae Shin ${ }^{1,2, *}$ \\ 1 Department of Marine Biotechnology, University of Science and Technology (UST), 217 Gajungro, \\ Yuseong-gu, Daejeon, 34113, Korea; choibk4404@kiost.ac.kr (B.-K.C.), caovananh@kiost.ac.kr (C.V.A.) \\ 2 Marine Natural Products Chemistry Laboratory, Korea Institute of Ocean Science and Technology, 385 \\ Haeyang-ro, Yeongdo-gu, Busan 49111, Korea; hwasunlee@kiost.ac.kr (H.-S.L.) \\ 3 Department of Applied Life Science, Graduate school of Konkuk University, Chungju 27478, Korea; \\ ifrecha@nate.com (S.-Y.P.), wowsong333@naver.com (S.-H.J.), choidk@kku.ac.kr (D.-K.C.) \\ 4 Nhatrang Institute of Technology Research and Application, Vietnam Academy of Science and Technology, \\ 02 Hung Vuong, Nha Trang, Vietnam; phanhoaitrinh84@gmail.com (P.T.H.T.); ngoduyngoc@nitra.vast.vn \\ (N.T.D.N); tranthanhvan@nitra.vast.vn (T.T.T.V.) \\ 5 Graduate University of Science and Technology, Vietnam Academy of Science and Technology, 18 Hoang \\ Quoc Viet, Cau Giay, Ha Noi, Vietnam \\ * Correspondence: shinhj@kiost.ac.kr; Tel.: +82-51-664-3341; Fax: +82-51-664-3340
}

\begin{abstract}
A new compound containing a triene, a tetrahydropyran ring and glycine ester functionalities, restricticin B (1), together with four known compounds (2-5) were obtained from the EtOAc extract of the marine fungus Penicillium janthinellum. The planar structure of $\mathbf{1}$ was determined by detailed analyses of MS, 1D and 2D NMR data. The relative and absolute configurations of 1 were established via analyses of NOESY spectroscopy data, comparison of optical rotation values with those of restricticin derivatives reported and electronic circular dichroism (ECD). All the compounds were screened for their anti-neuroinflammatory effects in lipopolysaccharide (LPS)-induced BV-2 microglia cells. Restricticin B (1) and N-acetyl restricticin (2) exhibited anti-neuroinflammatory effects by suppressing the production of pro-inflammatory mediators in activated microglial cells.
\end{abstract}

Keywords: restricticin; marine fungus; Penicillium janthinellum; BV-2 microglia cells; anti-inflammatory; rotamer

\section{Introduction}

The novel class of potent antifungal agents, restricticin and restricticinol, were first isolated from the fermentation broth of Penicillium restrictum [1,2]. These compounds contain a tetrahydropyran ring and triene side chains in common and restricticin possesses a glycine unit linked to the tetrahydropyran ring [3]. The initial biological activity study of restrciticin derivatives displayed that only restricticin exhibited potent antifungal activity against both yeast and filamentous fungi $[1$, 4]. The very closely related compounds with a shorter polyene chain, lanomycin and lanomycinol, were isolated from Pycnidiophora dispersa in 1992 [5, 6]. Lanomycin was active against some Candida species and dermatophytes and not active against Gram-positive, Gram-negative bacteria and Aspergillus fumigatus [7]. Resricticin and lanomycin were first reported as natural antifungal agents to inhibit cytochrome $\mathrm{P}_{450}$ lanosterol demethylase $[6,8]$. Interestingly, restricticinol and lanomycinol

*Corresponding author. Tel.: +82-51-664-3341; fax: +82-51-664-3340; e-mail: shinhj@kiost.ac.kr 
did not show such antifungal activity [8]. Because of considerable interest for biological activity, several methods for total synthesis of the antifungal agents have been described [8-10].

Microglia, macrophages and representative of the innate immune system in the brain, have been implicated as active contributors to neuron damage and readily become activated in response to infection or injury [11, 12]. Activated microglia up-regulate pro-inflammatory and neurotoxic mediators including tumor necrosis factor- $\alpha$ (TNF- $\alpha$ ), interleukin- $1 \beta$ (IL-1 $\beta)$, interleukin-6 (IL-6) and free radicals such as nitric oxide (NO) and superoxide [13]. Moreover, large numbers of activated microglia are present in CNS tissue of patients with chronic neurodegenerative diseases including Alzheimer disease, Parkinson disease, amyotrophic lateral sclerosis and prion disease [14, 15]. Therefore, the suppression of pro-inflammatory and neurotoxic molecules in activated microglia would be effective therapeutic approach to treat various neuronal diseases [16].

Over the past decade, the secondary metabolites from marine microbes have been researched for a novel chemical source for drug discovery and development [17, 18]. Among the marine-derived microbes, marine fungi produce bioactive compounds with a wide range of bioactivities such as antiviral, antibacterial, anticancer, antiplasmodial and anti-inflammatory [19]. As a part of our ongoing investigation for diverse secondary metabolites from marine microorganisms, we isolated the fungal 168CLC-17.1 strain from a sediment sample collected from $\mathrm{Cu}$ Lao Cham Island, Vietnam, and based on its 28S rRNA gene sequence, it was identified as Penicillium janthinellum. Further chemical investigation of the ethyl acetate extract of the fungal culture broth yielded a new restricticin derivative, named restricticin $B(\mathbf{1})$, together with four known compounds, $N$-acetyl restricticin (2) [19], 3,3"'-dihydroxy-6'- desmethyl terphenyllin (3) [20], fellutanine B (4) [21] and 10,23-dihydro-24,25-dehydro aflavinin (5) [22](Figure 1). Here, we describe the isolation, structure elucidation, and biological activities of these compounds.
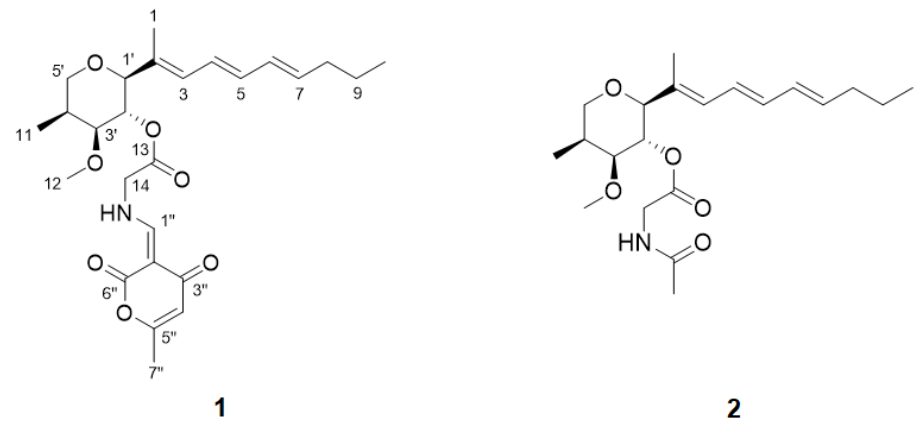

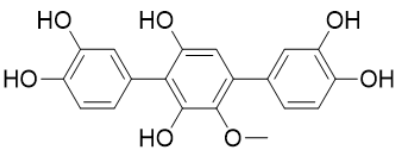

3

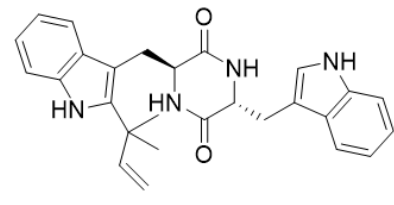

4

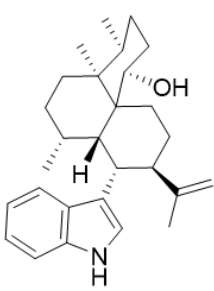

5

Figure 1. Structures of 1-5 isolated from Penicillium janthinellum.

\section{Results and Discussion}

Compound 1 was isolated as a pale brown oil and its molecular formula was determined to be $\mathrm{C}_{26} \mathrm{H}_{35} \mathrm{NO}_{7}$ based on the HRESIMS ion at $\mathrm{m} / \mathrm{z} 496.2306$ ([M+Na $]^{+}$calcd. 496.2311). In the ${ }^{1} \mathrm{H}$ NMR spectrum taken in $\mathrm{CD}_{3} \mathrm{OD}$ (Figure S2), 1 appeared as a 3:2 mixture of rotamers. The NMR data of the major rotamer are shown in Table 1 . The ${ }^{1} \mathrm{H}$ NMR spectrum of 1 indicated characteristic signals of seven olefinic protons $\left(\delta_{\mathrm{H}} 8.20,6.27,6.21,6.08,5.98,5.74\right.$, and 5.70$)$, four methine protons $\left(\delta_{\mathrm{H}} 5.00\right.$, $3.60,3.52$, and 2.33), four methylene protons $\left(\delta_{\mathrm{H}} 4.32, \delta_{\mathrm{H}} 3.78,3.63, \delta_{\mathrm{H}} 2.05\right.$, and $\left.\delta_{\mathrm{H}} 1.40\right)$ and five methyl protons $\left(\delta_{\mathrm{H}} 3.33,2.51,1.74,1.06\right.$, and 0.90$)$. The ${ }^{13} \mathrm{C}$ NMR spectrum, in combination with the 
HSQC spectrum, displayed the presence of 26 carbon signals, three carbonyl carbons $(\delta \mathrm{c} 184.1$, 164.9 , and 167.2), five pairs of olefinic carbons ( $\delta \mathrm{c} 165.4,162.7,135.3,134.4,132.5,130.6,129.5,125.3$, 106.9 , and 96.6$)$, three oxygenated methine carbons $(\delta c 84.9,81.0$, and 70.4$)$, one methine carbon $(\delta c$ 32.1 ), one oxygenated and one nitrogenated methylene carbons ( $\delta c 70.2$ and 50.0, respectively), two methylene carbons ( $\delta \mathrm{c} 34.5$ and 22.0), one methoxy carbon $(\delta c 55.0)$, and four methyl carbons $(\delta c$ 18.7, 12.6, 10.4, and 9.5). The planar structure of 1 was elucidated by analysis of the 2D NMR data, including the COSY and HMBC spectra (Figure 2). The COSY correlations of $\mathrm{H}-3 / \mathrm{H}-4 / \mathrm{H}-5 / \mathrm{H}-6 / \mathrm{H}-7 /$ $\mathrm{H}_{2}-8 / \mathrm{H}_{2}-9 / \mathrm{H}_{3}-10$ revealed the presence of an unsaturated side chain. The tetrahydropyran ring was confirmed by the COSY correlations of $\mathrm{H}-1^{\prime} / \mathrm{H}-2^{\prime} / \mathrm{H}-3^{\prime} / \mathrm{H}-4^{\prime} / \mathrm{H}_{2}-5^{\prime} / \mathrm{H}_{3}-11$ and the HMBC correlations from $\mathrm{H}-5^{\prime}$ to $\mathrm{C}-1^{\prime}, \mathrm{H}_{3}-12$ to $\mathrm{C}-3^{\prime}$, and $\mathrm{H}_{3}-11$ to $\mathrm{C}-3^{\prime}$ and $\mathrm{C}-5^{\prime}$. The HMBC correlations from $\mathrm{H}_{3}-1$ to $\mathrm{C}-1^{\prime}, \mathrm{C}-2$, and $\mathrm{C}-3, \mathrm{H}-1^{\prime}$ to $\mathrm{C}-2$ and $\mathrm{C}-3$, and $\mathrm{H}-2^{\prime}$ to $\mathrm{C}-2$ indicated that the triene side chain is connected to the tetrahydropyran ring. The geometry of the side chain was determined as all $E$ by the large ${ }^{3} \mathrm{H}, \mathrm{H}$ coupling constants for $\mathrm{H}-4 / \mathrm{H}-5$ (14.5 ppm) and H-6/H-7 (15.0 ppm) and the NOESY correlations of $\mathrm{H}-3 / \mathrm{H}-5$ and $\mathrm{H}_{3}-1 / \mathrm{H}-4$. Afterward, a glycine moiety was confirmed by the HMBC correlations from H-2' and $\mathrm{H}_{2}-14$ to C-13. Detailed analysis of 1D and 2D NMR spectra of 1 revealed that the partial structure was closely similar to that of restricticin. The HMBC correlations from $\mathrm{H}-1$ " to C-2", C-3", C-6", and C-14, H-4" to C-2" and C-5", and H-7" to C-4" and C-5" established the $\alpha$-pyrone moiety linked to $\mathrm{NH}$ of the glycine unit. In addition, the NMR data in specific area showed the proton and carbon signals of the above-mentioned rotamers (Table S1). The ${ }^{1} \mathrm{H}$ NMR spectrum of 1 displayed a pair of olefinic singlet signals at $\mathrm{H}-1$ " (major: $\delta \mathrm{H} 8.20$, minor: $\delta_{\mathrm{H}} 8.32$ ) and doublet methylene signals at $\mathrm{H}-14$ (major: $\delta_{\mathrm{H}} 4.27,4.36$, minor: $\delta_{\mathrm{H}} 4.29,4.38$ ). Moreover, a pair of signals for the exchangeable $\mathrm{NH}$ proton (major: $\delta_{\mathrm{H}} 11.8$, minor: $\delta_{\mathrm{H}} 10.1$ ) was detected in the ${ }^{1} \mathrm{H}$ NMR spectrum in $\mathrm{CDCl}_{3}$. The ${ }^{13} \mathrm{C}$ NMR spectrum also showed a doubling of signals in the glycine and $\alpha$-pyrone residues, corresponding to three pairs of carbonyls, two pairs of olefinic carbons, two pairs of quaternary carbons, and a pair of a nitrogenated methylene carbon. We discussed here only the structure elucidation of the major rotamer for clarity.

(A)

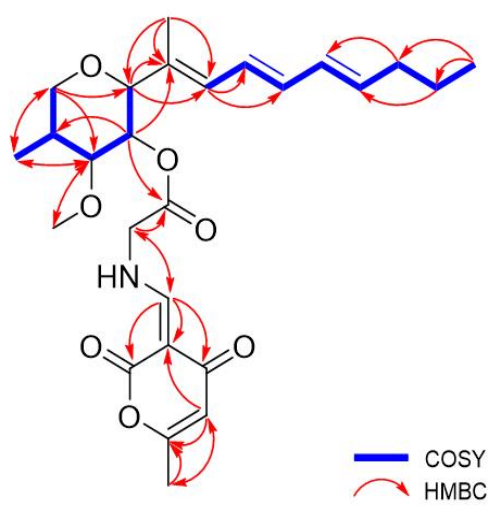

(B)

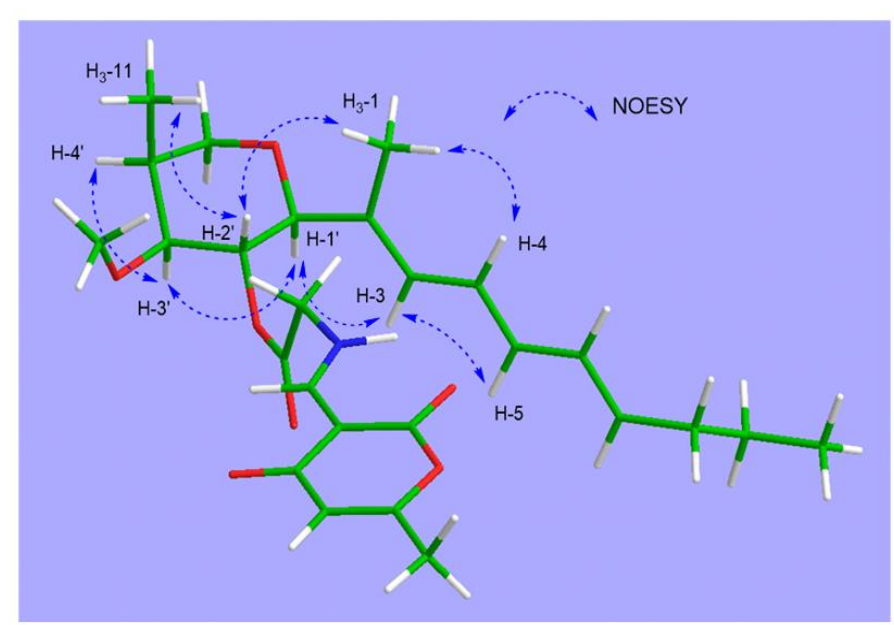

Figure 2. (A) Key COSY and HMBC correlations of 1. (B) Key NOESY correlations of 1.

The relative stereochemistry of $\mathbf{1}$ was determined by the analysis of NOESY spectra and the comparison of the optical rotation values with literatures. The strong NOESY correlations of $\mathrm{H}_{3}-1 / \mathrm{H}-2^{\prime} / \mathrm{H}_{3}-11$ and $\mathrm{H}-1^{\prime} / \mathrm{H}-3^{\prime} / \mathrm{H}-4^{\prime}$ suggested that $\mathrm{H}_{3}-1, \mathrm{H}-10$ and $\mathrm{H}_{3}-11$ were on the same face, and $\mathrm{H}-\mathbf{1}^{\prime}, \mathrm{H}-3^{\prime}$ and $\mathrm{H}-4^{\prime}$ were on the opposite face. Finally, the absolute configuration of $\mathbf{1}$ was confirmed by comparison of the specific rotation value of 1 with those in the literature [8-10, 22](Figure 3) and electronic circular dichroism(ECD) method (Figure 4). The optical rotation value 
Table 1. ${ }^{1} \mathrm{H}$ and ${ }^{13} \mathrm{C}$ NMR data for 1 and 2 at $500 \mathrm{MHz}$ and $125 \mathrm{MHz}$ in $\mathrm{CD}_{3} \mathrm{OD}(\delta$ in ppm, $J$ in $\mathrm{Hz})$

\begin{tabular}{|c|c|c|c|c|c|c|}
\hline \multirow{2}{*}{ Position } & \multicolumn{3}{|c|}{1} & \multicolumn{3}{|c|}{ N-Acetyl restricticin (2) } \\
\hline & $\delta_{\mathrm{H}}(J$ in $\mathrm{Hz})$ & Type & $\delta \mathrm{c}$ & $\delta$ н $(J$ in $\mathrm{Hz})$ & Type & $\delta \mathrm{c}$ \\
\hline $1^{\prime}$ & $3.60(\mathrm{~d}, 9.5)$ & $\mathrm{CH}$ & 84.9 & $3.60(\mathrm{~d}, 9.5)$ & $\mathrm{CH}$ & 85.0 \\
\hline $2^{\prime}$ & $5.00(\mathrm{dd}, 9.5,9.5)$ & $\mathrm{CH}$ & 70.4 & $4.98(\mathrm{dd}, 9.5,9.5)$ & $\mathrm{CH}$ & 67.7 \\
\hline $3^{\prime}$ & $3.52, \mathrm{~m}$ & $\mathrm{CH}$ & 81.0 & $3.47, \mathrm{~m}$ & $\mathrm{CH}$ & 81.3 \\
\hline $4^{\prime}$ & 2.33, $\mathrm{m}$ & $\mathrm{CH}$ & 32.1 & 2.30, $\mathrm{m}$ & $\mathrm{CH}$ & 32.4 \\
\hline \multirow[t]{2}{*}{$5^{\prime}$} & $3.63(\mathrm{~d}, 12.0)$ & $\mathrm{CH}_{2}$ & 70.2 & $3.64(\mathrm{~d}, 12.0)$ & $\mathrm{CH}_{2}$ & 70.3 \\
\hline & $3.78(\mathrm{~d}, 12.0)$ & & & $3.75(\mathrm{~d}, 12.0)$ & & \\
\hline 1 & 1.74. s & $\mathrm{CH}_{3}$ & 10.4 & 1.78. s & $\mathrm{CH}_{3}$ & 10.5 \\
\hline 2 & & $\mathrm{C}$ & 132.5 & & C & 132.5 \\
\hline 3 & $5.98(\mathrm{~d}, 10.5)$ & $\mathrm{CH}$ & 129.5 & $5.99(\mathrm{~d}, 10.5)$ & $\mathrm{CH}$ & 129.4 \\
\hline 4 & $6.27(\mathrm{dd}, 14.5,10.0)$ & $\mathrm{CH}$ & 125.3 & $6.27(\mathrm{dd}, 14.5,10.5)$ & $\mathrm{CH}$ & 125.6 \\
\hline 5 & $6.21(\mathrm{dd}, 14.5,10.0)$ & $\mathrm{CH}$ & 134.4 & $6.23(\mathrm{dd}, 14.5,10.5)$ & $\mathrm{CH}$ & 134.0 \\
\hline 6 & $6.08(\mathrm{dd}, 15.0,10.5)$ & $\mathrm{CH}$ & 130.6 & $6.10(\mathrm{dd}, 14.5,10.5)$ & $\mathrm{CH}$ & 130.7 \\
\hline 7 & $5.70,(\mathrm{dt}, 15.0,7.0)$ & $\mathrm{CH}$ & 135.3 & $5.72,(\mathrm{dt}, 14.5,7.0)$ & $\mathrm{CH}$ & 135.0 \\
\hline 8 & $2.05(\mathrm{q}, 7.0)$ & $\mathrm{CH}_{2}$ & 34.5 & $2.07(q, 7.0)$ & $\mathrm{CH}_{2}$ & 34.5 \\
\hline 9 & $1.40, \mathrm{~m}$ & $\mathrm{CH}_{2}$ & 22.0 & $1.44, \mathrm{~m}$ & $\mathrm{CH}_{2}$ & 22.1 \\
\hline 10 & $0.90(t, 7.5)$ & $\mathrm{CH}_{3}$ & 12.6 & $0.91(t, 7.0)$ & $\mathrm{CH}_{3}$ & 12.6 \\
\hline 11 & $1.06(\mathrm{~d}, 7.0)$ & $\mathrm{CH}_{3}$ & 9.5 & $1.06(\mathrm{~d}, 7.5)$ & $\mathrm{CH}_{3}$ & 9.6 \\
\hline 12 & $3.33, \mathrm{~s}$ & $\mathrm{OCH}_{3}$ & 55.0 & $3.34, \mathrm{~s}$ & $\mathrm{OCH}_{3}$ & 55.4 \\
\hline 13 & & $\mathrm{C}$ & 167.2 & & C & 169.1 \\
\hline \multirow[t]{2}{*}{14} & $4.27(\mathrm{~d}, 18.0)$ & $\mathrm{CH}_{2}$ & 50.0 & $3.73(\mathrm{~d}, 18.0)$ & $\mathrm{CH}_{2}$ & 40.5 \\
\hline & $4.36(\mathrm{~d}, 18.0)$ & & & $3.94(\mathrm{~d}, 18.0)$ & & \\
\hline $\mathrm{NH}^{\mathrm{a}}$ & $11.8, \mathrm{brs}$ & & & & & \\
\hline $1^{\prime \prime}$ & $8.20, \mathrm{~s}$ & $\mathrm{CH}$ & 162.7 & & C & 172.0 \\
\hline $2^{\prime \prime}$ & & $\mathrm{C}$ & 96.6 & $1.95, \mathrm{~s}$ & $\mathrm{CH}_{3}$ & 20.8 \\
\hline $3^{\prime \prime}$ & & $\mathrm{C}$ & 184.1 & & & \\
\hline $4^{\prime \prime}$ & $5.74, \mathrm{~s}$ & $\mathrm{CH}$ & 106.9 & & & \\
\hline $5^{\prime \prime}$ & & $\mathrm{C}$ & 165.4 & & & \\
\hline $6^{\prime \prime}$ & & C & 164.9 & & & \\
\hline $7^{\prime \prime}$ & $2.51, \mathrm{~s}$ & $\mathrm{CH}_{3}$ & 18.7 & & & \\
\hline
\end{tabular}

The assignments were aided by COSY, NOESY, HSQC, and HMBC NMR spectra. ${ }^{a}$ Measured in $\mathrm{CDCl}_{3}$

of $\mathbf{1}$ is in good agreement with all reported restrciticins, lanomycins and N-acetyl restricticin (2), suggesting that 1 has the same absolute configuration with its derivatives as shown in Figure 3. Additionally, ECD calculation of enantiomers $\left(1: 1^{\prime} S, 2^{\prime} R, 3^{\prime} S, 4^{\prime} S\right.$, ent $\left.-1: 1^{\prime} R, 2^{\prime} S, 3^{\prime} R, 4^{\prime} R\right)$ was carried out at B3LYP/6-311 + G(d)1 level. The experimental CD spectrum showed a positive Cotton effect at $305 \mathrm{~nm}$. Then, the calculated ECD spectrum of $1 \mathbf{a}$ was in good agreement with the experimental CD spectrum, suggesting the absolute configurations of $\mathbf{1}$ are defined as $1^{\prime} \mathrm{S}, 2^{\prime} \mathrm{R}, 3^{\prime} \mathrm{S}, 4^{\prime} \mathrm{S}$. Based on these results, the structure of $\mathbf{1}$ was determined and named restricticin $B$.

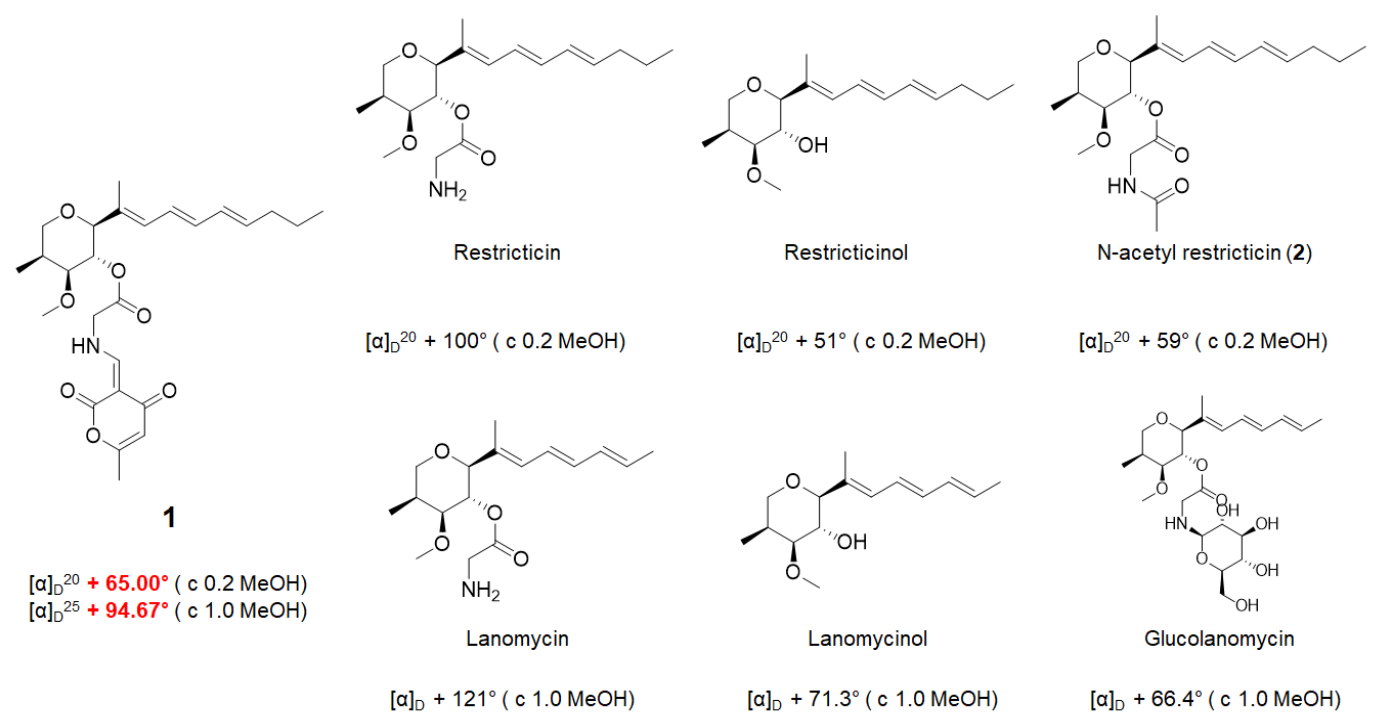

Figure 3. Comparison of optical rotation value of 1 with reference compounds. 


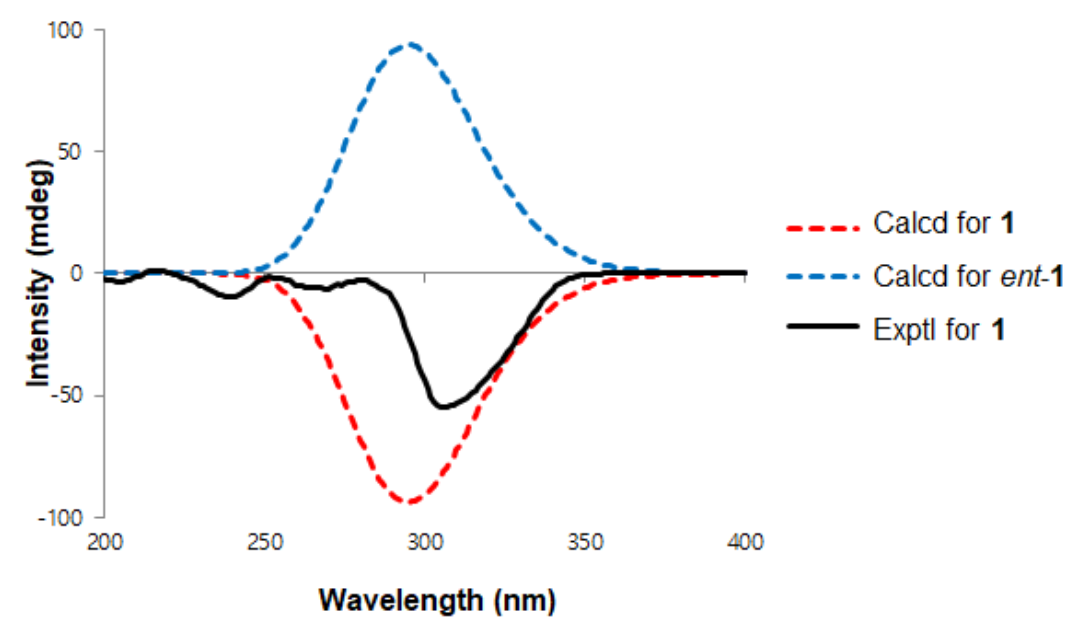

Figure 4. Comparison of experimental CD curve of $\mathbf{1}$ with calculated ECD spectra of $\mathbf{1}$ and ent-1.

The structures of the four known compounds were determined as $N$-acetyl restricticin (2), 3,3"'-dihydroxy-6'-desmethyl terphenyllin (3), fellutanine B (4) and 10,23-dihydro-24,25-dehydro aflavinin (5) by comparing their ${ }^{1} \mathrm{H},{ }^{13} \mathrm{C}$ NMR and MS data with those reported in literature (Supporting information).

Compounds $\mathbf{1}$ and $\mathbf{2}$ were tested for their antimicrobial activity using fungi (Penicillium italicum KCTC 6437, Rhizopus oryzae KCTC 6944), yeast (Candida albicans KCTC 7678), Gram-positive bacteria (Micrococcus lutes KCTC1915, Staphylococcus auresus KCTC 1927, Bacillus subtilis KCTC 1021) and Gram-negative bacteria (Salmonella typhimurium KCTC 2515, Klebsiella pneumoniae KCTC 2690, Escherichia coli KCTC 2441) and the cytotoxicity against cancer cell lines (HCT-15, NUGC-3, NCI-H23, ACHN, PC-3 and MDA-MB-231). However, 1 and $\mathbf{2}$ showed no antibacterial activity and cytotoxicity against cancer cell lines. Along with the fact that restrictinol and lanomycinol have no antifungal activity in previous research, the results of this study suggested that the free amine of the glycine unit is important for the antifungal activity.
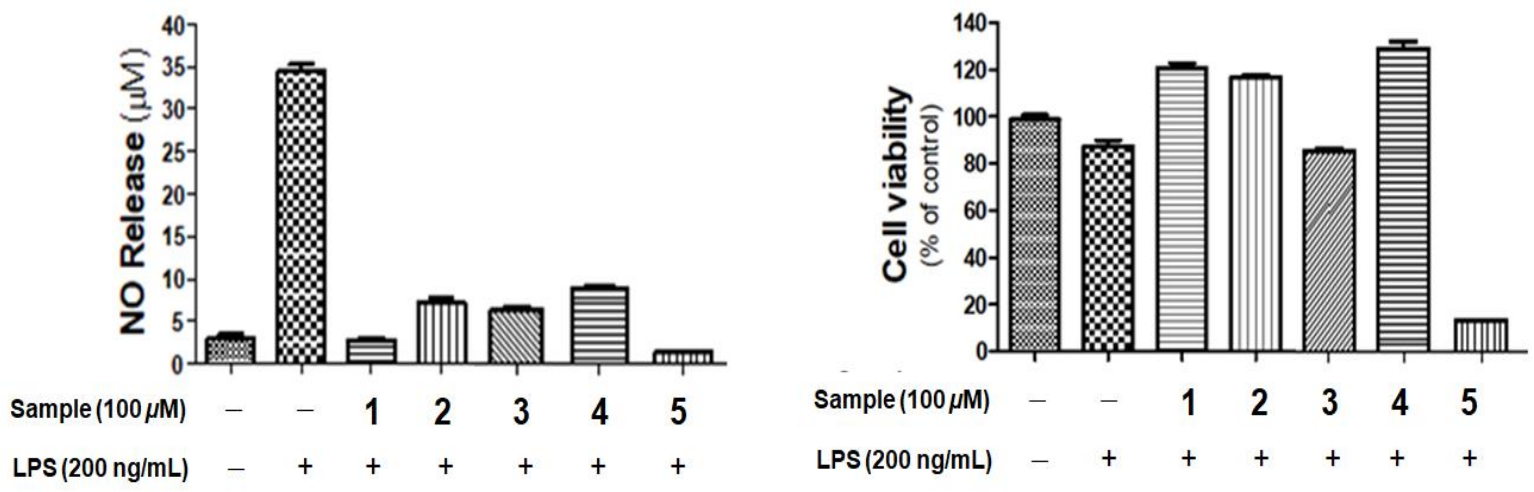

Figure 5. The effects of compounds 1-5 on NO production in LPS-stimulated BV-2 cells. Cells were pretreated with the indicated concentration of samples for $1 \mathrm{~h}$ and then stimulated with LPS (100 $\mathrm{ng} / \mathrm{mL}$ ) for $24 \mathrm{~h}$. Cell viability was evaluated using MTT assay. Results are shown as percentage of control samples. Values are mean \pm standard error.

All the isolated compounds (1-5) were evaluated for inhibitory activity on nitric oxide (NO) production in LPS-stimulated BV-2 microglial cells and for their cytotoxicity. The cells were initially treated with $100 \mu \mathrm{M}$ concentration of each compounds and/or LPS $(200 \mathrm{ng} / \mathrm{mL})$ to measure the levels of NO and cytotoxicity using MTT assay. As shown in Figure 5, all the compounds inhibited 
the LPS-induced NO production in BV-2 microglial cells. However, compounds $\mathbf{3}$ and $\mathbf{5}$ displayed weak and strong toxicity, respectively. Compounds 1, 2, and 4 decreased the production of NO without showing cytotoxicity at the treated concentrations. According to the results, restricticin derivatives have the most potent anti-inflammatory effect among the treated compounds without cytotoxicity. Therefore, restricticin B (1) and N-acetyl restricticin (2) were selected to further investigate the effects on LPS-induced expression of inducible nitric oxide synthase (iNOS) and cyclooxygenase-2 (COX-2) mRNA and protein expression, and production of LPS-stimulated pro-inflammatory cytokines in BV-2 microglia cells.

Two restricticin compounds ( 1 and 2$)$ at $50 \mu \mathrm{M}$ and $100 \mu \mathrm{M}$ concentrations inhibited the NO production in BV-2 cells in a dose dependent manner (Figure 6A). Compound 1 showed stronger inhibition of NO production than 2. As shown in Figure 6B and 6C, LPS treatment $(200 \mathrm{ng} / \mathrm{mL})$ significantly upregulated iNOS and COX-2 expression, and the mRNA and protein expression levels of iNOS and COX-2 were inhibited by restricticins in a concentration-dependent manner. To investigate whether restricticins repress the production of pro-inflammatory cytokines such as TNF- $\alpha$, IL- $1 \beta$ and IL-6, RT-PCR was performed, and the results showed that restricticins reduced the secretion of proinflammatory cytokines. Interestingly, IL-1 $\beta$ was the most strongly inhibited by compound 1 at the $100 \mu \mathrm{M}$ concentration. Consequently, these results indicated that restricticins have effective properties in neuroinflammation processes and suppress the expression of proinflammatory mediators at the transcriptional level.

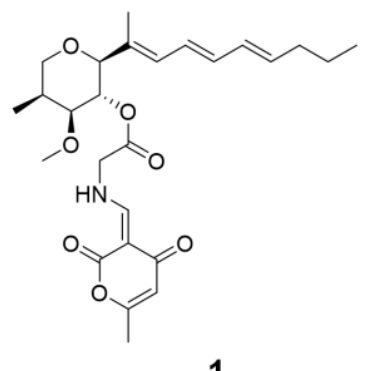

1

(A)

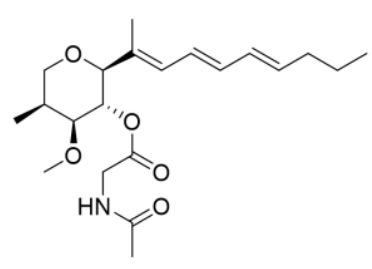

2
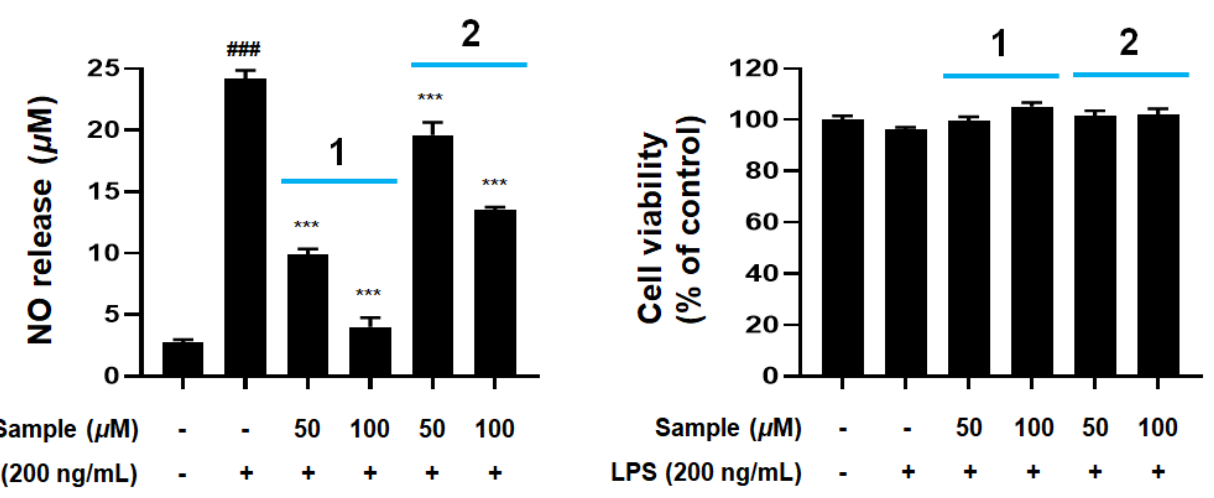

Figure 6. Cont. 
(B)

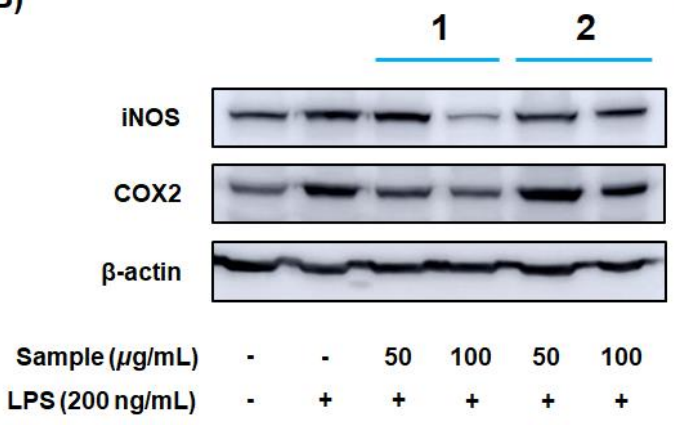

(C)

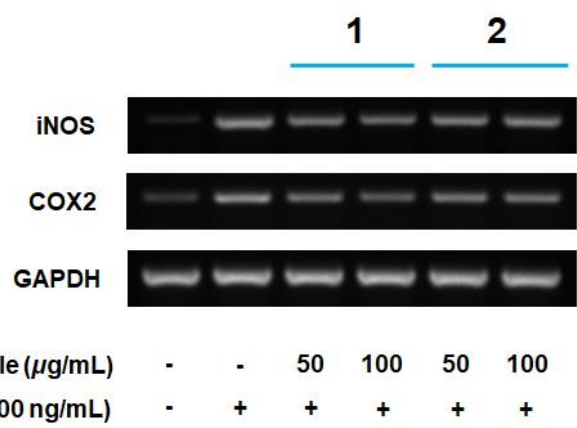

(D)

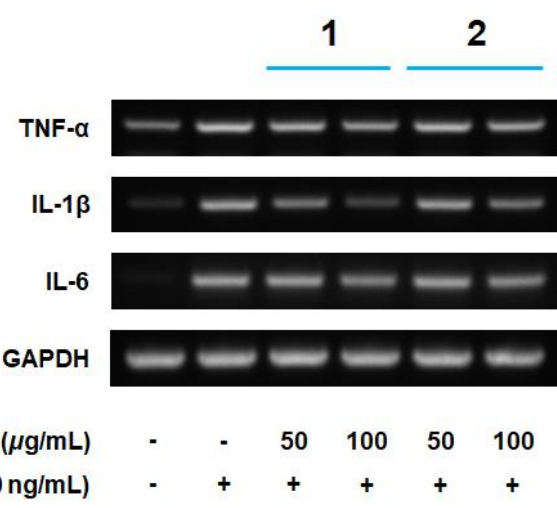

Figure 6. (A) The nitrite levels were measured in the culture media using the Griess reaction. Cell viability was evaluated using the MTT assay. Results are shown as percentage of control samples. (B) Suppression of iNOS and COX-2 protein (C) and mRNA (D) and pro-inflammatory cytokines expression by compounds 1-2 in LPS-stimulated BV-2 cells. The corresponding quantification data were shown in the each panel respectively. GAPDH and $\beta$-actin were used as internal controls, respectively. The results are expressed as relative signal intensity for two independent experiments $\left(B, C\right.$, and D). Values are mean \pm standard error. \#\# $p<0.001$, vs. control group and ${ }^{*} p<0.05,{ }^{* *} p<$ 0.01 and ${ }^{* * *} p<0.001$ vs. LPS-treated group.

\section{Materials and Methods}

\subsection{General Experimental Procedures}

1D $\left({ }^{1} \mathrm{H}\right.$ and $\left.{ }^{13} \mathrm{C}\right)$ and 2D (COSY, HSQC, HMBC and NOESY) NMR spectra were measured on a Varian Unity $500 \mathrm{MHz}$ and a Bruker $600 \mathrm{MHz}$ spectrometer with TMS as an internal standard. Optical rotations were obtained on a Rudolph Research Analytical (Autopol III) polarimeter. CD spectra were measured on a JASCO J-1500 spectrometer. UV spectra were acquired on a Shimadzu UV-1650PC spectrophotometer. IR spectra were recorded on a JASCO FT/IR-4100 spectrophotometer. HRESIMS were measured on a hybrid ion-trap time-of-flight mass spectrometer (Shimadzu LC/MS-IT-TOF). HPLC system was composed of a PrimeLine Binary pump with RI-101(Shodex). Semi-preparative HPLC was performed using an ODS column (YMC-Pack-ODS-A, $250 \times 10 \mathrm{~mm}$ i.d, $5 \mu \mathrm{m}$ ). Analytical HPLC was conducted on an ODS column (YMC-Pack-ODS-A, 250 $\times 4.6 \mathrm{~mm}$ i.d, $5 \mu \mathrm{m})$.

\subsection{Reagents}

Lipopolysaccharide (LPS), dimethyl sulfoxide (DMSO), 3-(3, 4-dimethylthiazole-2-yl)-2, 5-diphenyl-tetrazoliumbromide (MTT), sulfanilamide, H3PO4 and N-1(1-naphthyl)ethylene diamine dihydrochloride were obtained from Sigma-Aldrich. The $10 \times$ RIPA buffer was obtained from Millipore. Protease inhibitor and phosphatase inhibitor cocktail tablets were purchased from Roche. Plastic wares (6-well, 24-well tissue culture plates and $100 \mathrm{~mm}$ culture dishes) were 
purchased from SPL. Dulbecco's modified Eagle's medium (DMEM), fetal bovine serum (FBS), 1x trypsin-EDTA (TE), and 100,000 U/ml penicillin-streptomycin (P-S) were obtained from Gibco/Invitrogen. Primary antibodies anti-COX-2 (1:1000) was obtained from Abcam and Calbiochem. Anti- $\beta$-actin (1:5000) and anti-iNOS (1:1000) were procured from Sigma-Aldrich and BD Biosciences, respectively. Secondary antibodies anti-mouse (1:2000) and anti-rabbit (1:2000) were obtained from Cell Signaling Technology and Bio-Rad.

\subsection{BV-2 Microglial cell culture and Treatment}

The BV-2 microglial cells were cultured in Dulbecco's modified Eagle medium supplemented with $5 \%$ fetal bovine serum and $1 \%$ penicillin/streptomycin $(100$ units $/ \mathrm{mL})$ at $37^{\circ} \mathrm{C}$ in a humidified $5 \% \mathrm{CO}_{2}$ incubator. The cell was seeded at a density of $2.5 \times 10^{5}$ cells $/ \mathrm{mL}$ and pretreated same concentration of samples and followed by LPS incubation $(200 \mathrm{ng} / \mathrm{mL})$ [24].

\subsection{Cell viability and Nitrite assay}

The BV-2 microglial cells seeded at a density of $2.5 \times 10^{5}$ cells/well were pretreated with 100 $\mu \mathrm{M}$ single concentration of compounds 1-5 for $1 \mathrm{~h}$, followed by LPS(200 ng/mL) for $24 \mathrm{~h}$. $20 \mu \mathrm{L}$ of MTT solution ( $2 \mathrm{mg} / \mathrm{mL}$, conc.) was added to each well in 24 well. After $1 \mathrm{~h}$ supernatant was sucked and dissolved the formazan crystals in viable cells from DMSO. Optical density was measured at $550 \mathrm{~nm}$ using a microplate reader and values were determined in comparison to control cells. For nitrite assay, the BV-2 microglial cells seeded at a density of $2.5 \times 10^{5}$ cells/well were pretreated with $100 \mu \mathrm{M}$ single concentration of compounds 1-5 for $1 \mathrm{~h}$, followed by LPS (200 ng/mL) for $24 \mathrm{~h}$. 100 $\mu \mathrm{L}$ of supernatants collected, transferred to new microplate. After transfer, assayed for NO release using Griess reagent ( 1 vol. $0.1 \%$ naphthylethylenediamine and 1 vol. $1 \%$ sulfanilamide in $5 \% \mathrm{H}_{3} \mathrm{PO}_{4}$ ) and a range of sodium nitrite dilutions was used to obtain a standard curve with the amount of nitrite in each sample. Absorbance was determined at $540 \mathrm{~nm}$ using a microplate reader [24].

\subsection{Total RNA Extraction and Reverse transcription polymerase chain reaction (RT-PCR)}

Total RNA was extracted from BV-2 microglial cells using Trizol reagent (Invitrogen Life Technologies) according to the manufacturer's instructions. RNA $(2.5 \mu \mathrm{g})$ was reverse-transcribed using ReverTra Ace- $\alpha$ kit (Toyobo) according to the manufacturer's instruction. PCR amplification was performed using specific primers (Bioneer)[25].

\subsection{Western Blot Analysis}

Treated BV-2 cells $\left(5 \times 10^{5}\right.$ cells/well) was washed twice with PBS and lysed for 10 min using 1 $\mathrm{x}$ RIPA lysis buffer at $4{ }^{\circ} \mathrm{C}$. Cell lysates was centrifuged at $14,000 \mathrm{rpm}$ at $4{ }^{\circ} \mathrm{C}$ and the corresponding supernatants were collected and separately stored for further analysis. The protein concentration of each sample was obtained using a DC Protein Assay kit (Bio-Rad). Equal amounts of protein (35 $\mu \mathrm{g}$ for cells) were separated electrophoretically by $10 \%$ sodium dodecyl sulfate-polyacrylamide electrophoresis, and the resolved proteins were transferred to polyvinylidene difluoride membranes. The membranes were incubated for $1 \mathrm{~h}$ with $5 \%$ Skim-milk in TBS buffer to block nonspecific binding. The blots were visualized by a PowerOpti-ECL kit obtained from the detection system (Animal Genetics Inc.)[25].

\subsection{Fungal strain and Fermentation}

The strain 168CLC-17.1 was isolated from a sediment sample, collected at $\mathrm{Cu}$ Lao Cham Island, Quang Nam, Vietnam in August 2016. The strain was identified by DNA amplification and sequencing of the ITS region (GenBank accession number AB293968.1) and named as Penicillium janthinellum 168CLC-17.1. The fungal strain was cultured on a potato dextrose agar (PDA) for a week and then the grow-well strain was inoculated on rice medium at $28^{\circ} \mathrm{C}$ for 22 days in 80 
Erlenmeyer flasks $(500 \mathrm{~mL})$, each containing rice $(20.0 \mathrm{~g})$, yeast extract $(20.0 \mathrm{mg}), \mathrm{KH}_{2} \mathrm{PO}_{4}(10 \mathrm{mg})$, and natural sea water $(40 \mathrm{~mL})$ as reported previously [26].

\subsection{Isolation of Compounds 1-5}

The mycelia and rice media were extracted with EtOAc and then concentrated to yield a crude extract $(6 \mathrm{~g})$. The crude extract was fractionated by flash column chromatography on ODS using a gradient of $\mathrm{MeOH} / \mathrm{H}_{2} \mathrm{O}(1: 4,2: 3,3: 2,4: 1$ and $100 \% \mathrm{MeOH}$, each fraction $300 \times 3)$. The third fraction eluted with $80 \% \mathrm{MeOH}$ was purified with a semi-preparative reversed-phase HPLC $(2.0 \mathrm{~mL} / \mathrm{min}$, RI detector, $\left.22 \% \mathrm{MeCN} / \mathrm{H}_{2} \mathrm{O}\right)$ to obtain $1\left(7.5 \mathrm{mg}, \mathrm{tr}_{\mathrm{R}}=28 \mathrm{~min}\right)$ and $2\left(3.2 \mathrm{mg}\right.$, $\left.\mathrm{t}_{\mathrm{R}}=18 \mathrm{~min}\right)$. The first fraction eluted with $40 \% \mathrm{MeOH}$ was further separated into ten subfractions ( $\mathrm{Fr}$. A-H) by column chromatography on ODS eluting with a step gradient of $\mathrm{MeOH} / \mathrm{H}_{2} \mathrm{O}(20: 80$ to 40:60, v/v). Fr. B (82 $\mathrm{mg}$ ) was subjected to a semi-preparative reversed-phase HPLC (YMC-Pack-ODS-A, $250 \times 10 \mathrm{~mm}$ i.d, $5 \mu \mathrm{m}$, flow rate $3.0 \mathrm{~mL} / \mathrm{min}$, RI detector) using isocratic elution with $25 \% \mathrm{MeOH}$ in $\mathrm{H}_{2} \mathrm{O}$ to yield 3 $(62 \mathrm{mg}, \mathrm{t}=14 \mathrm{~min})$. Compound $4\left(5.1 \mathrm{mg}, \mathrm{t}_{\mathrm{R}}=46 \mathrm{~min}\right)$ was isolated from the third fraction eluted with $60 \% \mathrm{MeOH}$ by a semi-preparative reversed-phase HPLC $(3.0 \mathrm{~mL} / \mathrm{min}$, RI detector, $55 \%$ $\mathrm{MeOH} / \mathrm{H}_{2} \mathrm{O}$ ). The first fraction eluted with $100 \% \mathrm{MeOH}$ was further separated into ten subfractions (Fr. A-J) by column chromatography on ODS eluting with a step gradient of $\mathrm{MeOH} / \mathrm{H}_{2} \mathrm{O}$ (90:10 to 100:0, v/v). Fr. C-F (182 mg) was purified by a semi-preparative reversed-phase HPLC (YMC-Pack-ODS-A, $250 \times 10 \mathrm{~mm}$ i.d, $5 \mu \mathrm{m}$, flow rate $4.0 \mathrm{~mL} / \mathrm{min}$, RI detector) using isocratic elution with $95 \% \mathrm{MeOH}$ in $\mathrm{H}_{2} \mathrm{O}$ to yield 5 ( $85 \mathrm{mg}$, $\mathrm{t}_{\mathrm{R}}=12 \mathrm{~min}$ ).

Restricticin B (1): pale brown oil ; $[\alpha]_{\mathrm{D}}^{20}+65$ (c 0.2, MeOH); CD (MeOH), $\lambda_{\max }(\Delta \varepsilon) 305$ (54.59) nm; IR $\nu_{\max } 2933,1727,1653,1617,1458,1328,1201,1109,1035,985 \mathrm{~cm}^{-1}$; UV(MeOH) $\lambda_{\max }(\log \varepsilon) 317$ (3.39), 276 (3.77), 236 (3.47), 201 (3.53) nm; HRESIMS m/z 496.2306 [M + Na] ${ }^{+}$(calcd for 496.2311, $\left.\mathrm{C}_{26} \mathrm{H}_{35} \mathrm{NO} 7 \mathrm{Na}\right) ;{ }^{1} \mathrm{H}$ NMR $\left(\mathrm{CD}_{3} \mathrm{OD}, 500 \mathrm{MHz}\right)$ and ${ }^{13} \mathrm{C} \mathrm{NMR}\left(\mathrm{CD}_{3} \mathrm{OD}, 125 \mathrm{MHz}\right)$ see Table 1.

\subsection{Calculation of ECD spectra}

Conformational searches were performed by CONFLEX version 8.0 program (CONFLEX Corporation) with molecular mechanics force field (MMFF) within window of $3.0 \mathrm{kcal} / \mathrm{mol}$. The conformers were further optimized by the B3LYP/6-311G $(\mathrm{d}, \mathrm{p})$. The theoretical calculations of the ECD data were conducted using the TD-DFT method at the B3LYP/6-311G $(\mathrm{d}, \mathrm{p})$, which were performed with Gaussian 16 software (Gaussian Inc.). The calculated ECD spectra data were averaged based on their Boltzmann populations.

\section{Conclusions}

Two restrciticin derivatives (1 and 2), along with three known compounds (3-5) were isolated from the rice medium cultures of the marine-derived fungus Penicillium janthinellum 168CLC-17.1. The structures of the isolated compounds were determined by analysis of their NMR and mass spectrometric data. The absolute configuration of restricticin B (1) was established by NOESY correlations, comparison of specific rotation values with those of restricticin derivatives reported and electronic circular dichroism (ECD). Interestingly, the new restricticin possessed an $\alpha$-pyrine ring connected to $\mathrm{NH}$ of glycine moiety and showed signal duplication as a 3:2 mixture of rotamers. Two isolated restricticins exhibited inhibitory activity on NO production in LPS-stimulated BV-2 microglial cells. Moreover, the restricticins suppressed iNOS and COX-2 expression (both at the protein and mRNA levels), and also inhibited LPS-induced production of pro-inflammatory cytokines. Additionally, compound 1 possessing $\alpha$-pyrone moiety linked to $\mathrm{NH}$ showed stronger activity than 2 containing $\mathrm{N}$-acetyl group. To the best of our knowledge, this is the first report on the anti-neuroinflammatory activity of restrciticins. 
Supplementary Materials: The followings are available online at www.mdpi.com/link, Figures S1-S8, Table S1: HRESI-MS data, ${ }^{1} \mathrm{H}$ NMR, ${ }^{13} \mathrm{C}$ NMR, COSY, HSQC, HMBC, NOESY, experimental spectra, Figure S21, Table S2-S8 : ECDs of 1, Figures S9-S20: LRMS data, ${ }^{1} \mathrm{H}$ NMR, ${ }^{13} \mathrm{C}$ NMR and experimental spectra of 2-5.

Author Contributions: H.J.S. was the principal investigator, who proposed ideas for the present work, managed and supervised the whole research work, prepared and corrected the manuscript, and contributed to the structure elucidation of the new and known compounds. B.-K.C. achieved all experiments for compounds 1-5, including fermentation, isolation, and structure elucidation, and prepared the manuscript. P.T.H.T., H.-S.L., C.V.A., N.T.D.N. and T.T.T.V. contributed to analyzing data. S.-Y.P., S.-H.J. and D.-K.C. performed the experiments related to anti-neuroinflammation of $\mathbf{1 - 5}$.

Funding: This research was supported in part by the Korea Institute of Ocean Science and Technology (Grant PE99852) and the Ministry of Oceans and Fisheries, Republic of Korea (Grant PM59122).

Acknowledgments: The authors express gratitude to Dr. Young Hye Kim, Korea Basic Science Institute, Ochang, Korea, for providing mass data. Authors would like to thank the Vietnam Government for allowing us to do marine microbial research.

Conflicts of Interest: The authors declare no conflict of interest.

\section{References}

1. Schwartz Robert, E.; Abruzzo George, K.; Jenkins, R.; Glazomitsky, K.; Bills, G.; Zitano, L.; Val Sagrario Mochales, D. E. L.; Omstead Mary, N.; Dufresne, C.; Flor James, E.; Kempf August, J.; Wilson Kenneth, E.; Lam, T.; Onishi, J.; Milligan, J.; Fromtling Robert, A., Restricticin, a novel glycine-containing antifungal agent. J. Antibiot. 1991, 44, 463-471.

2. Matsukuma, S.; Ohtsuka, T.; Kotaki, H.; Shirai, H.; Sano, T.; Watanabe, K.; Nakayama, N.; Itezono, Y.; Fujiu, M.; Shimma, N.; et al., A new series of natural antifungals that inhibit P450 lanosterol C-14 demethylase. I. Taxonomy, fermentation, isolation and structural elucidation. J. Antibiot. 1992, 45, 151-9.

3. Hensens, O. D.; Wichmann, C. F.; Liesch, J. M.; VanMiddlesworth, F. L.; Wilson, K. E.; Schwartz, R. E., Structure elucidation of restricticin, a novel antifungal agent from penicillium restrictum. Tetrahedron 1991, 47, 3915-3924.

4. Tsukuda, T.; Shiratori, Y.; Watanabe, M.; Ontsuka, H.; Hattori, K.; Shirai, M.; Shimma, N., Modeling, synthesis and biological activity of novel antifungal agents (1). Bioorg. Med. Chem. Lett. 1998, 8, 1819-24.

5. O'Sullivan, J.; Phillipson, D. W.; Kirsch, D. R.; Fisher, S. M.; Lai, M. H.; Trejo, W. H., Lanomycin and glucolanomycin, antifungal agents produced by Pycnidiophora dispersa. I. Discovery, isolation and biological activity. J. Antibiot. 1992, 45, 306-12.

6. Phillipson, D. W.; O'Sullivan, J.; Johnson, J. H.; Bolgar, M. S.; Kahle, A. D., Lanomycin and glucolanomycin, antifungal agents produced by Pycnidiophora dispersa. II. Structure elucidation. J. Antibiot. 1992, 45, 313-9.

7. Aoki, Y.; Yamazaki, T.; Kondoh, M.; Sudoh, Y.; Nakayama, N.; Sekine, Y.; Shimada, H.; Arisawa, M., A new series of natural antifungals that inhibit P450 lanosterol C-14 demethylase. II. Mode of action. J. Antibiot. 1992, 45, 160-70.

8. Barrett, A. G. M.; Bennett, A. J.; Menzer, S.; Smith, M. L.; White, A. J. P.; Williams, D. J., Applications of Crotonyldiisopinocampheylboranes in Synthesis: Total Synthesis of Restrictinol. J. Org. Chem. 1999, 64, 162-171.

9. Honda, T.; Satoh, A.; Yamada, T.; Hayakawa, T.; Kanai, K., Stereoselective construction of the key intermediate for the synthesis of the tetrahydropyranyl antifungal agents (+)-restricticin and (+)-lanomycin. J. Chem. Soc., Perkin Trans. 1 1998, 3, 397-406.

10. Kang, S. H.; Kim, C. M., Total Synthesis of (+)-Lanomycin. Synlett 1996, 6, 515-516.

11. Block, M. L.; Zecca, L.; Hong, J. S., Microglia-mediated neurotoxicity: uncovering the molecular mechanisms. Nat. Rev. Neurosci. 2007, 8, 57-69.

12. Perry, V. H.; Nicoll, J. A.; Holmes, C., Microglia in neurodegenerative disease. Nat. Rev. Neurol. 2010, 6, 193-201.

13. Napoli, I.; Neumann, H., Microglial clearance function in health and disease. Neuroscience 2009, 158, 1030-8.

14. Cameron, B.; Landreth, G. E., Inflammation, microglia, and Alzheimer's disease. Neurobiol. Dis. 2010, 37, 503-9. 
15. Griffin, W. S.; Stanley, L. C.; Ling, C.; White, L.; MacLeod, V.; Perrot, L. J.; White, C. L., 3rd; Araoz, C., Brain interleukin 1 and S-100 immunoreactivity are elevated in Down syndrome and Alzheimer disease. Proc. Natl. Acad. Sci. U.S.A. 1989, 86, 7611-5.

16. Liu, B.; Hong, J. S., Role of microglia in inflammation-mediated neurodegenerative diseases: mechanisms and strategies for therapeutic intervention. J. Pharmacol. Exp. Ther. 2003, 304, 1-7.

17. Penesyan, A.; Kjelleberg, S.; Egan, S., Development of Novel Drugs from Marine Surface Associated Microorganisms. Mar. Drugs 2010, 8, 438.

18. Barzkar, N.; Tamadoni Jahromi, S.; Poorsaheli, H. B.; Vianello, F., Metabolites from Marine Microorganisms, Micro, and Macroalgae: Immense Scope for Pharmacology. Mar. Drugs 2019, 17, 464.

19. Raimundo, I.; Silva, S. G.; Costa, R.; Keller-Costa, T., Bioactive Secondary Metabolites from Octocoral-Associated Microbes-New Chances for Blue Growth. Mar. Drugs 2018, 16, 485.

20. Liu, J.-K., Natural Terphenyls: Developments since 1877. Chem. Rev. 2006, 106, 2209-2223.

21. Kozlovsky, A. G.; Vinokurova, N. G.; Adanin, V. M.; Burkhardt, G.; Dahse, H.-M.; Gräfe, U., New Diketopiperazine Alkaloids from Penicillium fellutanum. J. Nat. Prod. 2000, 63, 698-700.

22. TePaske, M. R.; Gloer, J. B.; Wicklow, D. T.; Dowd, P. F., Three new aflavinines from the sclerotia of aspergillus tubingensis. Tetrahedron 1989, 45, 4961-4968.

23. Paterson, I.; Nowak, T., Anti Aldol reactions of $\alpha$-alkoxymethyl ketones: Application to the total synthesis of (+)-restricticin. Tetrahedron Lett. 1996, 37, 8243-8246.

24. Kim, B. W.; Koppula, S.; Kim, I. S.; Lim, H. W.; Hong, S. M.; Han, S. D.; Hwang, B. Y.; Choi, D. K., Anti-neuroinflammatory activity of Kamebakaurin from Isodon japonicus via inhibition of c-Jun $\mathrm{NH}(2)$-terminal kinase and p38 mitogen-activated protein kinase pathway in activated microglial cells. J. Pharmacol. Sci. 2011, 116, 296-308.

25. Jeon, N.-R.; Koppula, S.; Kim, B.-W.; Park, S.-H.; Lee, H.-W.; Choi, D.-K., MMHD [(S,E)-2-Methyl-1-(2-methylthiazol-4-yl) hexa-1,5-dien-ol], a Novel Synthetic Compound Derived From Epothilone, Suppresses Nuclear Factor-kB-Mediated Cytokine Expression in Lipopolysaccharide-Stimulated BV-2 Microglia. J. Pharmacol. Sci. 2010, 112, 158-166.

26. Choi, B.-K.; Phan, T. H. T.; Hwang, S.; Oh, D.-C.; Kang, J. S.; Lee, H.-S.; Ngo, T. D. N.; Tran, T. T. V.; Shin, H. J., Resorcinosides A and B, Glycosylated Alkylresorcinols from a Marine-Derived Strain of the Fungus Penicillium janthinellum. J. Nat. Prod. 2019, 82, 3186-3190. 